\title{
AZT resistance alters enzymatic properties and creates an ATP-binding site in SFVmac reverse transcriptase
}

\author{
Anna Schneider, Kristian Schweimer, Paul Rösch and Birgitta M Wöhrl
}

\begin{abstract}
Background: The replication of simian foamy virus from macaques can be inhibited by the nucleoside reverse transcriptase inhibitor azidothymidine (AZT, zidovudine). Four substitutions in the protease-reverse transcriptase (PR-RT) protein (K2111, 1224T, S345T, E350K) are necessary to obtain highly AZT resistant and fully replication competent virus. AZT resistance is based on the excision of the incorporated AZTMP in the presence of ATP. I224T is a polymorphism which is not essential for AZT resistance per se, but is important for regaining efficient replication of the resistant virus.

Results: We constructed PR-RT enzymes harboring one to four amino acid substitutions to analyze them biochemically and to determine their ability to remove the incorporated AZTMP. S345T is the only single substitution variant exhibiting significant AZTMP excision activity. Although K211I alone showed no AZTMP excision activity, excision efficiency doubled when K211I was present in combination with S345T and E350K. K211I also decreased nucleotide binding affinity and increased fidelity. NMR titration experiments revealed that a truncated version of the highly AZT resistant $m t 4$ variant, comprising only the fingers-palm subdomains was able to bind ATP with a $K_{D}$-value of ca. $7.6 \mathrm{mM}$, whereas no ATP binding could be detected in the corresponding wild type protein. We could show by NMR spectroscopy that S345T is responsible for ATP binding, probably by making a tryptophan residue accessible.

Conclusion: Although AZT resistance in SFVmac is based on excision of the incorporated AZTMP like in HIV-1, the functions of the resistance substitutions in SFVmac PR-RT appear to be different. No mutation resulting in an aromatic residue like F/Y215 in HIV, which is responsible for $\pi$ - $\pi$-stacking interactions with ATP, is present in SFVmac. Instead, S345T is responsible for creating an ATP binding site, probably by making an already existing tryptophan more accessible, which in turn can interact with ATP. This is in contrast to HIV-1 RT, in which an ATP binding site is present in the WT RT but differs from that of the AZT resistant enzyme.
\end{abstract}

Keywords: AZT resistance, ATP binding, Reverse transcriptase, NMR, Foamy virus, HIV

\section{Background}

Simian foamy virus from macaques (SFVmac) belongs to the subfamily of Spumaretrovirinae, which, together with the Orthoretrovirinae form the family of Retroviridae [1]. A considerable difference between the two subfamilies concerns the nature of the cleavage products of the Pol protein, which consists of the protease (PR), reverse transcriptase (RT) and integrase (IN) domains. While in orthoretroviruses the viral enzymes are cleaved

\footnotetext{
* Correspondence: birgitta.woehrl@uni-bayreuth.de

Universität Bayreuth, Lehrstuhl Biopolymere, Universitätsstr. 30, D-95447 Bayreuth, Germany
}

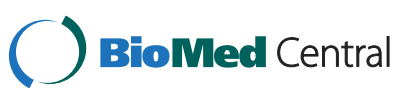

(c) 2015 Schneider et al.; licensee BioMed Central. This is an Open Access article distributed under the terms of the Creative Commons Attribution License (http://creativecommons.org/licenses/by/4.0), which permits unrestricted use, distribution, and reproduction in any medium, provided the original work is properly credited. The Creative Commons Public Domain Dedication waiver (http://creativecommons.org/publicdomain/zero/1.0/) applies to the data made available in this article unless otherwise stated. from a Gag-Pol precursor protein into PR, RT and IN, foamy viruses (FVs) possess a separate Pol precursor and do not cleave off the PR domain from the RT. Thus, the mature FV enzymes are PR-RT and IN $[2,3]$. The mature PR-RT is a monomeric protein with the PR (101 amino acid residues) located at its $\mathrm{N}$-terminus [3]. The PR is separated from the putative N-terminus of the RT domain via a stretch of 41 amino acid residues (region 102-143) whose presence appears to be important for RT integrity and proper orientation of the PR domain, which needs to dimerize in order to be active [4-7].

So far, only the human immunodeficiency (HIV) nucleotide RT inhibitor (NtRTI) tenofovir and the 
nucleoside RT inhibitor (NRTI) azidothymidine (AZT, zidovudine) have been shown to inhibit SFVmac replication [8-11]. Both substances are used for treating patients suffering from HIV infections.

Interestingly, both SFVmac and HIV-1 RT follow a similar AZT resistance mechanism: the incorporated chain terminating AZT-monophosphate (AZTMP) is excised in the presence of ATP [12-14]. It has been shown that the pyrophosphate donor in AZT resistant HIV-1 and SFVmac is ATP [12-14]. In HIV-1, the excision reaction products are a dinucleoside tetraphosphate (AZT$\mathrm{P}_{4}$ - $\mathrm{A}$ ) derived from ATP and AZTMP at the primer terminus and the resulting unblocked $3^{\prime} \mathrm{OH}$ primer [12]. Formation of the phosphodiester bond between ATP and AZTMP also requires specific ATP binding near the polymerase active site which orients the $\beta, \gamma$-phosphate moiety of ATP proximal to the phosphate group of AZTMP. Removal of AZTMP finally leads to primer rescue and elongation with natural dNTPs [15-17].

In SFVmac PR-RT four amino acid exchanges (K211I, I224T, S345T, E350K) are necessary to confer high resistance against AZT. Amino acid sequence alignments of the polymerase domains of SFVmac and HIV-1 revealed that the SFVmac AZT resistance mutations do not correspond to the ones obtained with highly AZTresistant HIV-1 RT (M41L, D67N, K70R, T215Y/F and K219Q/E) [12-14,17-21]. In HIV-1 the amino acid exchange T215Y/F is crucial for binding of ATP in the AZT resistant mutant RT. X-ray crystallography data revealed that both the WT and the AZT resistant RT are capable of ATP binding, however at different sites (site I and site II). The aromatic amino acid exchange T215F/Y in the resistant protein allows binding of ATP in site II and the formation of $\pi-\pi$ stacking interactions with the adenine ring of ATP, necessary for AZTMP excision [15,17].

Comparison of the AZT resistance mutations selected in HIV-1 and SFVmac shows that in SFVmac no exchange to an aromatic amino acid homologous to T215Y/F occurs. This raises the question as to what the functions of the individual mutations in the AZT resistant SFVmac RT are. We have shown previously that the amino acid exchange I224T is important for viral fitness but not for AZT resistance per se, i.e. it is not required for the AZTMP excision reaction [11,14].

Comparative studies on AZT resistance in ortho- and spumaretroviruses can shed light on the general requirements for AZTMP excision. HIV-1 and SFVmac achieve AZT resistance by AZTMP excision using different, non-homologous resistance pathways. In order to disclose the functions of the individual mutations for AZT resistance and the molecular mechanism in SFVmac PR$\mathrm{RT}$, we characterized the biochemical properties of various PR-RT variants harboring single, double, triple, and quadruple amino acid substitutions and analyzed the ability of the variants to excise AZTMP. Moreover, we examined ATP binding via NMR spectroscopy.

Here, we determined for the first time the molecular mechanism for AZT resistance in a monomeric RT as well as the dissociation constant for ATP in an AZT resistant retroviral RT.

\section{Results and discussion \\ Protein variants}

We have shown previously that the purified SFVmac PR-RTs $m t 3$ (K211I, S345K, E350K) and $m t 4$ (K211I, I224T, S345K, E350K) are able to excise AZTMP with similar efficiency from an AZTMP-terminated primer in the presence of ATP [14]. The I224T exchange in $m t 4$ is probably a polymorphism and does not contribute substantially to AZT-resistance but to viral fitness [11,14]. To reveal the individual contribution of the amino acid exchanges in SFVmac PR-RT for AZT resistance we analyzed various PR-RT enzymes with one to four amino acid substitutions in the polymerase domain. Additionally, all PR-RT enzymes used, carry a mutation in the PR domain leading to the active site residue exchange D24A. This renders the enzymes inactive as a protease. Thus, unintentional PR cleavage can be excluded.

RTs and several other DNA polymerases share a common three-dimensional structure, which is usually compared to the shape of a right hand with the so-called fingers, thumb, and palm subdomains [22-24]. The active site residues are located in the palm, while the thumb and fingers regions wrap around the nucleic acid substrate. Thus, the putative localization of the four exchanged amino acids in AZT resistant SFVmac PR-RT with regard to the polymerase active site could be determined by modeling the structure of the SFVmac polymerase domain with the Program SWISS-MODEL [25] using xenotropic murine leukemia-like related virus (XMRV) RT (pdb: 4HKQ) with a sequence homology of approximately $29 \%$ as a template [22] (Figure 1). Similarly to SFVmac PR-RT this enzyme is also monomeric. The model shows that the polymorphism I224T is located at some distance to the active site residues YVDD, while S345T and E350K are positioned in the palm subdomain next to the active site and thus could be involved in ATP-binding. K211I is part of a loop in the fingers subdomain, homologous to the beta $\beta 3-\beta 4$ loop in HIV-1 RT. In HIV-1 RT this loop contains the basic amino acids $\mathrm{K} 65$ and R72 that interact with the phosphates of an incoming dNTP. These residues have been shown to be important for polymerization activity, drug resistance, and fidelity [26,27].

\section{Polymerization properties}

To show that the purified recombinant proteins harboring one to four amino acid exchanges (Figure 2A) were 


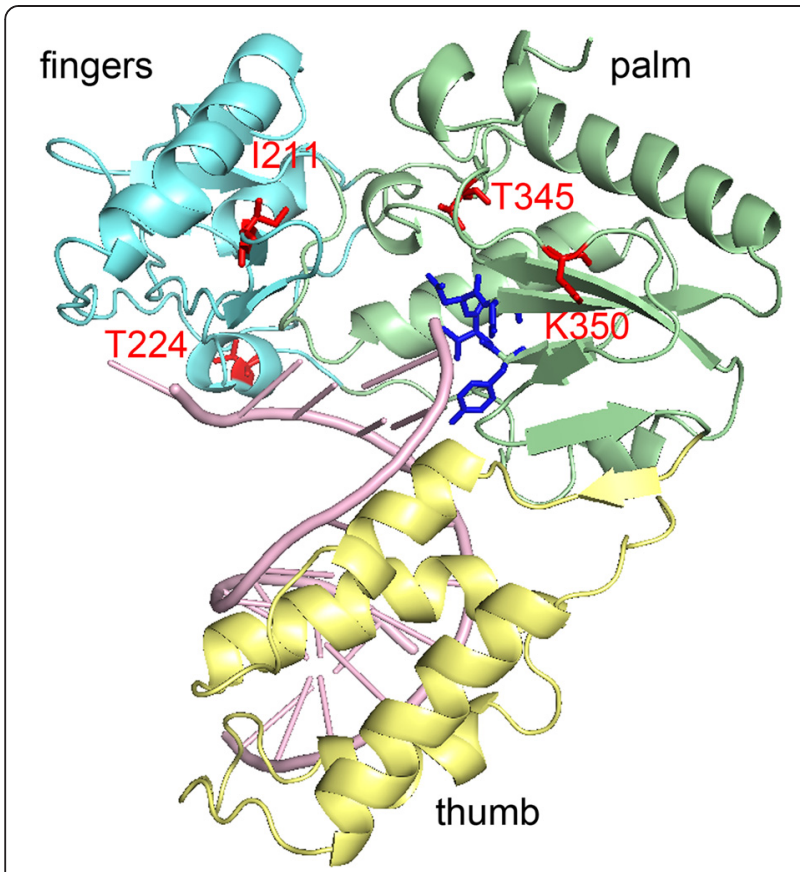

Figure 1 Localization of the AZT resistance substitutions. The putative locations of the four substituted amino acid residues in the highly resistant $m t 4(1211, \mathrm{~T} 224, \mathrm{~T} 345, \mathrm{~K} 350)$ are highlighted in red in a structural model of the SFVmac RT polymerase domain. The polymerase active site motif YVDD is highlighted in blue. The model is based on the structure of XMRV RT (PDB: 4HKQ) with an RNA/DNA hybrid substrate and was generated using the Program SWISS-MODEL [25]. still active as polymerases we determined their specific acitvities on a poly(rA)/oligo(dT) substrate (Table 1). Obviously, the K211I exchange results in severely reduced polymerization activity since the single as well as the double variants harboring K211I $(m t 2 a, m t 2 b)$ are impaired. In contrast, $m t 2 c$ lacking K211I exhibits high polymerization activity. Remarkably, the specific polymerization activity of E350K is significantly higher than that of the WT.

Since the specific activities of the variants containing K211I were considerably lower than the WT activities, we performed primer extension assays with a 30/50mer DNA/DNA $\left(\mathrm{P}_{30} / \mathrm{T}_{50}\right)$ substrate which was $5^{\prime}{ }^{32} \mathrm{P}$ endlabeled at the primer. Conditions were chosen that allowed the investigation of the first nucleotide addition steps (Figure 2B) to determine whether the enzymes are impaired in initiating polymerization. Although all proteins were able to extend the primer by a few nucleotides, K211I appeared to be the least active enzyme among the single exchange variants. Accordingly, $m t 2 a$ and $m t 2 b$, also harboring the K211I substitution, were less efficient in initiating polymerization than $m t 2 c$. The latter shows an even higher activity than the WT. These data are also reflected in the specific polymerization activities measured with the homopolymeric substrate poly (rA)/oligo(dT) (Table 1). Interestingly, due to the presence of K211I, the activity of $m t 3$ is reduced as compared to the WT. However, the polymerization behavior of $m t 4$ is again comparable to the WT owing to the presence of the polymorphism I224T.

\section{AZT resistance}

AZT resistance in SFVmac is based on the removal of the incorporated AZTMP in the presence of ATP [14]. Therefore, to elucidate the function of the individual
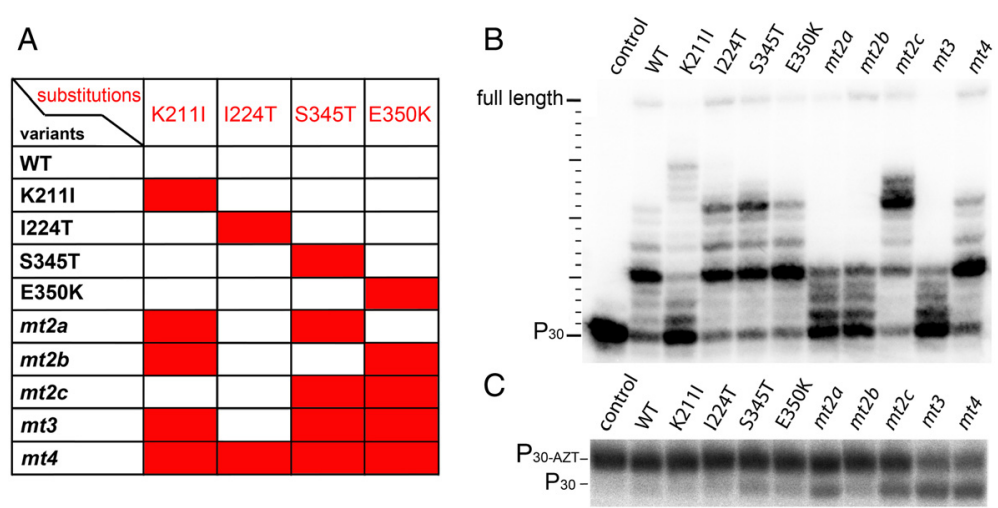

Figure 2 Polymerization activity and AZT resistance of SFVmac PR-RT variants. (A). SFVmac PR-RT variants used in this study harboring one to four of the relevant resistance substitutions are highlighted by red rectangles. (B) Polymerization initiation. Initiation of polymerization was

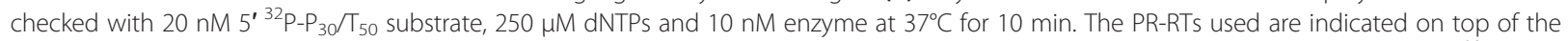
gel. WT, wild type; Control, sample without enzyme. (C) AZTMP removal in the presence of ATP. 5 nM of an AZTMP-terminated and 5' ${ }^{32}$ P-labeled substrate $\mathrm{P}_{30 \text {-AZTMP }} / \mathrm{T}_{50}, 0.02 \mathrm{U}$ of pyrophosphatase and $5 \mathrm{mM}$ ATP were preincubated for $5 \mathrm{~min}$. Reactions were started by the addition of 320 $\mathrm{nM}$ enzyme as indicated on top and stopped after $20 \mathrm{~min}$. Reaction products were separated on $10 \%$ sequencing gels and visualized by phosphoimaging. $P_{30-A Z T}$, AZTMP terminated primer; $P_{30}$, unblocked primer. 
Table 1 Specific polymerization activities and AZT resistance of SFVmac PR-RTs and corresponding viruses

\begin{tabular}{|c|c|c|c|c|c|}
\hline \multirow[t]{2}{*}{ Enzyme } & \multirow[t]{2}{*}{${ }^{1} \mathrm{SPAC}$} & \multirow[t]{2}{*}{$p$-value } & \multirow{2}{*}{$\begin{array}{l}{ }^{2} \text { AZTMP } \\
\text { excision } \\
(\%)\end{array}$} & \multicolumn{2}{|c|}{${ }^{3}$ Viral titer in \% } \\
\hline & & & & w/o AZT & $5 \mu \mathrm{M}$ AZT \\
\hline WT & $28.6( \pm 3.1)$ & - & $3.0( \pm 1.1)$ & 100 & $<0.1$ \\
\hline K211I & $7.0( \pm 4.8)$ & 0.005 & $2.4( \pm 1.4)$ & $1.2( \pm 1.2)$ & $<0.1$ \\
\hline I224T & $22.5( \pm 10.3)$ & 0.410 & $3.5( \pm 1.4)$ & $146.5( \pm 21.4)$ & 0.1 \\
\hline S345T & $28.8( \pm 8.3)$ & 0.977 & $10.4( \pm 1.2)$ & $40.0( \pm 16.8)$ & $1.1( \pm 1.0)$ \\
\hline E350K & $44.7( \pm 2.1)$ & 0.003 & $2.8( \pm 0.7)$ & $31.7( \pm 8.8)$ & $<0.1$ \\
\hline$m t 2 a$ & $13.3( \pm 0.9)$ & 0.009 & $14.5( \pm 0.7)$ & $<0.1$ & $<0.1$ \\
\hline$m t 2 b$ & $8.7( \pm 2.9)$ & 0.001 & $7.9( \pm 0.6)$ & $23.0( \pm 7.9)$ & $<0.1$ \\
\hline$m t 2 c$ & $32.6( \pm 13.8)$ & 0.667 & $18.7( \pm 1.2)$ & $20.6( \pm 5.5)$ & $3.0( \pm 2.1)$ \\
\hline$m t 3$ & $15.5( \pm 2.6)$ & 0.005 & $35.4( \pm 0.6)$ & $8.6( \pm 2.7)$ & $2.8( \pm 1.3)$ \\
\hline$m t 4$ & $21.7( \pm 3.9)$ & 0.079 & $37.9( \pm 1.3)$ & $113.0( \pm 19.2)$ & $68.8( \pm 18.8)$ \\
\hline
\end{tabular}

substitutions for AZT resistance, we tested the AZTMP excision efficiency using a $5{ }^{32} \mathrm{P}$-endlabeled and AZTMPterminated primer/template substrate $\left(\mathrm{P}_{30-\mathrm{AZT}} / \mathrm{T}_{50}\right)$ and $5 \mathrm{mM}$ ATP (Figure 2C, Table 1). Only one of the singly substituted variants, i.e. S345T, showed significant ( $>5 \%)$ AZTMP excision activity. This indicates that S345T is the key amino acid exchange for AZTMP removal. As shown above, the inability of the other single variants to remove incorporated AZTMP is not due to a lack of polymerization activity (Table 1, Figure 2B). We have shown previously that the single amino acid exchange S345T leads to moderate drug resistance of the virus in the presence of $0.5-5 \mu \mathrm{M}$ AZT. However, in the absence of AZT it resulted in reduced viral titer (40\%) as compared to the WT virus [11] (Table 1).

Among the enzyme variants carrying two substitutions, a combination of the key exchange S345T with K211I ( $m t 2 a)$ improved the excision efficiency as compared to S345T alone from ca. 10 to $15 \%$, and the combination of S345T with E350K $(m t 2 c)$ almost doubled the excision efficiency (ca. 19\%) (Table 1). In contrast, $m t 2 b$, lacking the S345T substitution, exhibited no significant AZTMP removal activity.

Remarkably, the virus harboring the corresponding substitutions of $m t 2 a$ was not able to replicate, neither in the presence nor in the absence of AZT, although the purified PR-RT variant still showed polymerization activity, albeit reduced (Figure 2B). Virus $m t 2 c$ exhibited moderate AZT resistance, but in the absence of AZT the viral fitness was reduced to ca. $20 \%$ as compared to the WT virus [11] (Table 1). These data imply that E350K might be the second AZT resistance mutation, since the combination of the putative first exchange S345T with
K211I leads to replication deficient virus (Table 1). The combination of K211I and E350K ( $m t 2 b)$ showed little AZTMP excision in vitro. This was reflected in cell culture assays with the corresponding virus, which was unable to replicate in the presence of $5 \mu \mathrm{M}$ AZT [11] (Table 1). Obviously, the K211I exchange on its own and in $m t 2 a$ yields replication deficient virus (Figure 2B, Table 1) [11]. However, in $m t 3$ the presence of K211I supported AZTMP removal. Compared to $m t 2 c$, the excision efficiency of $m t 3$ was about 2 -fold higher (Table 1 ). Moreover, the high excision activity was retained with $m t 4$, confirming that I224T improves viral fitness in the fully resistant virus but is not involved in AZT resistance per se. This was also illustrated by the fact that the dramatic decrease of viral titer with the $m t 3$ virus $(8.6 \%$ of the WT virus) in the absence of AZT was fully compensated by $\mathrm{I} 224 \mathrm{~T}$ in the $m t 4$ virus, bringing the titer back to WT levels (ca. 113\%) (Table 1) [11].

Taken together, these data show that the single substitution S345T results in moderate ATZMP excision activity, which can be further improved in combination with K211I or E350K. The major gain in AZTMP excision efficiency is due to the additional exchange K211I. However, this substitution leads to an impaired polymerization reaction, which can be recovered in $m t 4$ by I224T.

\section{RNase $\mathrm{H}$ activities}

In HIV-1 RT certain substitutions in the connection subdomain or RNase $\mathrm{H}$ domain leading to a reduced RNase $\mathrm{H}$ activity can enhance AZT resistance on a DNA/RNA primer/template. Slowing down the RNase $\mathrm{H}$ activity allows the enzyme more time for AZTMP excision to take place [28-30]. To investigate whether the substitutions 
in SFVmac PR-RT, although not in the connection subdomain or RNase $\mathrm{H}$ domain, influence the RNase $\mathrm{H}$ activity, we performed qualitative RNase $\mathrm{H}$ assays with a 5' ${ }^{32} \mathrm{P}$-endlabeled $\mathrm{RNA}_{25} / \mathrm{DNA}_{22}$ substrate (Figure 3 ). However, no significant reduction of the RNase $\mathrm{H}$ activities could be detected. Rather, quantification of the cleavage products indicated that E350K exhibits a significantly higher RNase $\mathrm{H}$ activity than all the other enzymes. Apart from this effect no significant differences, e.g. in the cleavage pattern, could be detected, implying no influence of the RNase $\mathrm{H}$ activity on AZT resistance.

\section{Kinetic parameters for polymerization and DNA binding}

To further assess the effect of the K211I substitution on AZT resistance, we determined the kinetic parameters of the enzymes (Table 2). The reduced polymerization

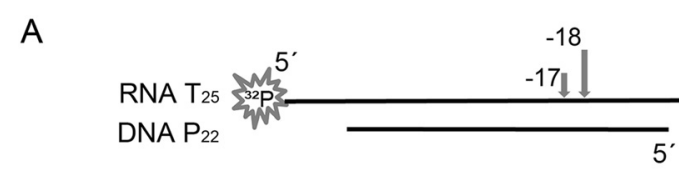

B

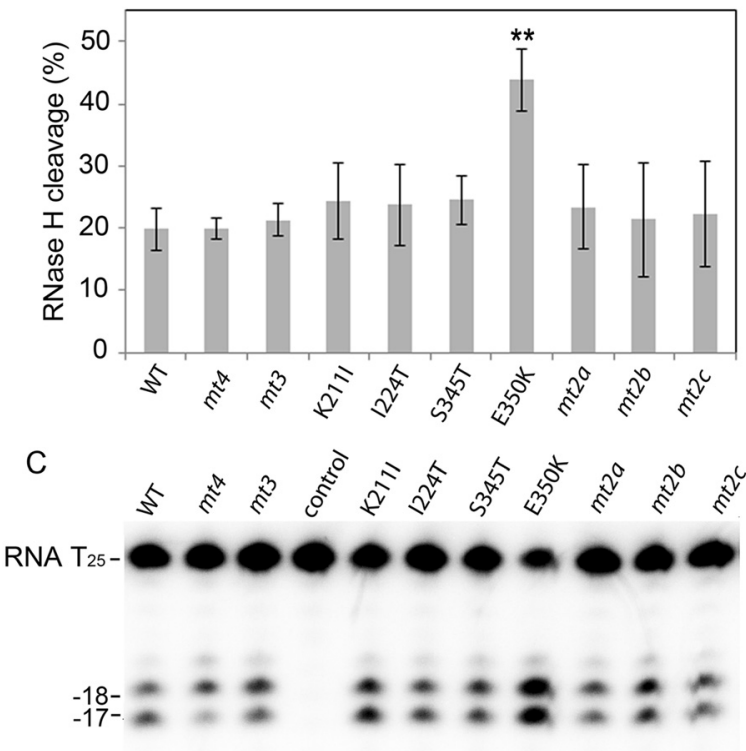

Figure 3 Qualitative RNase $\mathbf{H}$ assay. (A) Schematic representation of the $5^{\prime}{ }^{32} \mathrm{P}-\mathrm{RNA}_{25} / \mathrm{DNA} \mathrm{A}_{22}$ hybrid. The arrows on top of the RNA indicate the major RNase $\mathrm{H}$ cleavage sites at position -17 and -18 . The first nucleotide of the RNA hybridized to the $3^{\prime}-\mathrm{OH}$ nucleotide of the DNA strand is designated -1. (B) Quantification of the RNase $\mathrm{H}$ cleavage products. The diagram depicts the mean values and standard deviations (black bars) of three independent experiments. For quantification of the cleavage products the total amount of labeled RNA per lane was set to $100 \%$. Only the $\mathrm{p}$-value of E350K $\left.\leq 0.01{ }^{(* *}\right)$ represents a statistically significant difference to the WT protein. (C) Autoradiogram of a typical RNase $\mathrm{H}$ cleavage experiment. RNase $\mathrm{H}$ reactions were performed with $240 \mathrm{nM} 5^{\prime 32} \mathrm{P}_{-} \mathrm{RNA}_{25} / \mathrm{DNA}_{22}$ hybrid and $50 \mathrm{nM}$ RT-PR for 2 min at $25^{\circ} \mathrm{C}$. RNA $\mathrm{T}_{25}$, uncleaved RNA; $-17,18$ indicate the cleavage sites; control, reaction mix without enzyme.
Table 2 Kinetic parameters of SFVmac PR-RTs for polymerization and DNA binding

\begin{tabular}{|c|c|c|c|c|}
\hline Enzyme & ${ }^{1} \mathrm{~K}_{\mathrm{M}}(\mu \mathrm{M})$ & $\begin{array}{l}{ }^{1} V_{\max } \\
(\mathrm{mM} / \mathrm{min})\end{array}$ & $\begin{array}{l}\mathrm{V}_{\max } / \mathrm{K}_{\mathrm{M}} \\
(1 / \mathrm{min})\end{array}$ & $\begin{array}{l}{ }^{2} K_{\mathrm{D}} \mathrm{P} / \mathrm{T} \\
(\mathrm{nM})\end{array}$ \\
\hline WT & $57( \pm 7)$ & $2.1( \pm 0.08)$ & $36.8( \pm 4.7)$ & $9.6( \pm 0.7)$ \\
\hline K211I & $160( \pm 28)$ & $0.3( \pm 0.02)$ & $1.9( \pm 0.4)$ & $19.6( \pm 2.3)$ \\
\hline I224T & $94( \pm 9)$ & $2.2( \pm 0.08)$ & $23.4( \pm 2.4)$ & $8.9( \pm 1.4)$ \\
\hline S345T & $34( \pm 6)$ & $1.1( \pm 0.05)$ & $32.4( \pm 5.9)$ & $8.7( \pm 0.9)$ \\
\hline E350K & $32( \pm 8)$ & $1.8( \pm 0.10)$ & $56.3( \pm 14.4)$ & $9.7( \pm 1.7)$ \\
\hline$m t 2 a$ & $252( \pm 39)$ & $0.5( \pm 0.04)$ & $2.0( \pm 0.3)$ & $7.8( \pm 1.2)$ \\
\hline$m t 2 b$ & $159( \pm 41)$ & $0.6( \pm 0.02)$ & $3.8( \pm 1.0)$ & $15.8( \pm 2.5)$ \\
\hline$m t 2 c$ & $9( \pm 3)$ & $2.5( \pm 0.10)$ & $277.8( \pm 92.6)$ & $17.2( \pm 2.1)$ \\
\hline$m t 3$ & $67( \pm 14)$ & $2.0( \pm 0.10)$ & $29.9( \pm 6.2)$ & $15.8( \pm 2.1)$ \\
\hline$m t 4$ & $110( \pm 11)$ & $1.3( \pm 0.05)$ & $11.8( \pm 1.3)$ & $9.5( \pm 1.6)$ \\
\hline
\end{tabular}

${ }^{1} \mathrm{~K}_{\mathrm{M}}$ - and $\mathrm{v}_{\max }$-values were obtained by using the Michaelis-Menten equation to fit a curve to the data. ${ }^{2} \mathrm{~K}_{\mathrm{D}}$-values were obtained as described previously [14] by using an equation for a two state model to fit a curve to the titration data. Standard errors are given in parenthesis.

activity of variant K211I might be due to changes in affinities for the nucleic acid substrate and/or the dNTP. Determination of $\mathrm{K}_{\mathrm{M}^{-}}$and $\mathrm{v}_{\max }$-values as well as the $\mathrm{v}_{\max } / \mathrm{K}_{\mathrm{M}}$ ratio for nucleotide incorporation points in this direction. $\mathrm{K}_{\mathrm{M}}$-values of $\mathrm{K} 211 \mathrm{I}$ and variants harboring K211I ( $m t 2 b$ and $m t 2 a)$ were about 3 -fold $(m t 2 b)$ or 5 -fold $(m t 2 a)$ higher than that of the WT enzyme. In contrast, WT $\mathrm{v}_{\max }$ values are about 4- to 7-fold higher. E350K and $m t 2 c$ reach higher $\mathrm{v}_{\max } / \mathrm{K}_{\mathrm{M}}$-values than the WT, indicating higher catalytic activities (Table 2). However, this effect was obliterated by the introduction of K211I. The activity of the resulting $m t 3$ was again similar to the WT.

Fluorescence anisotropy measurements with a fluorescent labeled DNA/DNA $\mathrm{P} / \mathrm{T}$ resulted in similar $\mathrm{K}_{\mathrm{D}}$-values for all enzymes (Table 2). These findings confirm that K211I leads to an impairment of polymerization activity due to a decrease in nucleotide binding affinity, but not by altering the P/T binding affinity. Furthermore, substitution E350K and I224T appear to compensate the polymerization deficiency of $\mathrm{K} 211 \mathrm{I}$ in the $m t 3$ variant as well as in the highly resistant $m t 4$ protein.

\section{Fidelity}

The basic amino acid residues K65 und R72 in the $\beta 3$ $\beta 4$ loop region of the HIV-1 RT fingers subdomain not only have an impact on nucleotide binding affinity, but also on fidelity $[26,27,31]$. The fidelity of a polymerase describes the accuracy of nucleotide incorporation. Therefore, we investigated whether K211I, which is also positioned in the fingers subdomain, alters the SFVmac PR-RT's fidelity. We used a DNA/DNA $\mathrm{P}_{30} / \mathrm{T}_{50} \mathrm{dA}$ substrate labeled at the $5^{\prime}$ end of the primer to determine how efficient the primer can be elongated with a 
complementary (dTTP) or a mismatched dNTP (dATP) (Figure 4A). To overcome the reduced nucleotide binding affinity caused by K211I, a 5 -fold higher nucleotide concentration than in the polymerization assay was used for all enzymes.

In the presence of the complementary dTTP all enzymes extended the primer by one nucleotide with similar efficiency (Figure 4B, Additional file 1: Table S1), whereas additional nucleotide incorporations were due to mismatch events. In contrast, when non-templated dATP was used, primer extensions varied considerably (Figure 4C). Quantification of the extended primer after misincorporation disclosed that variant K211I, as well as $m t 2 a$ and $m t 2 b$, also harboring the K211I exchange, exhibited a significantly higher fidelity than the other enzymes, i.e. reduced incorporation efficiency for the mismatched dATP. $m t 2 c$, lacking the K211I substitution, showed a behavior similar to the WT enzyme (Figure 4C, Additional file 1: Table S1). In $m t 3$, S345T and E350K appear to compensate the effect of K211I, since $m t 3$, although containing the K211I exchange exhibited WT fidelity. Due to a decreased binding affinity for all dNTPs in enzymes harboring K211I, dissociation of the incorrect nucleotide and thereby correct base pairing is facilitated. This is similar to the results shown with the substitutions K65R and M184V/I in HIV-1 RT revealing an inverse correlation between fidelity and processivity or activity of the RT [26,27,32-35].

In $m t 3$ the reduced viral fitness of K211I is improved by S345T and E350K (Table 1), whereas the impaired fidelity caused by S345T and E350K is counteracted by K211I (Figure 4C). However, in order to restore viral fitness completely, the additional exchange I224T, resulting in $m t 4$, is required. Thus, some of the mutations in AZT resistant SFVmac RT $m t 4$ are not absolutely required for AZTMP removal but compensate the negative effects of the substitutions crucial for resistance.

\section{ATP binding analysis}

Interactions of proteins with ligands, e.g. ATP, can be investigated by NMR spectroscopy. An NMR spectrum of a ${ }^{15} \mathrm{~N}$ labeled protein, which correlates resonance frequencies of amide protons and directly bonded ${ }^{15} \mathrm{~N}$ labeled nitrogen atoms $\left(2 \mathrm{D}\left[{ }^{1} \mathrm{H}^{-15} \mathrm{~N}\right] \mathrm{HSQC}\right.$, heteronuclear single quantum correlation) allows the individual detection of peptide amide signals in the protein. Each signal represents a single amino acid of the peptide chain. Chemical shifts are very sensitive to the local structure of the protein. Changes in the chemical environment of amino acids, e.g. due to ATP binding, lead to chemical shift changes in the spectrum which indicate interactions between the protein and ATP.

Analysis of large proteins by NMR is limited due to extensive signal overlaps and a severe reduction in signal intensity. To obtain an RT small enough and suitable for NMR analysis, we constructed a truncated SFVmac polymerase domain lacking the thumb but comprising the fingers and palm subdomains that contain all four amino acid substitutions for AZT resistance. In previous work, we have already determined the starting point of the RT domain at residue 107 of the PR-RT enzyme. Deletion of the PR at that residue provides a soluble and catalytically active RT [4]. Based on sequence alignments with a catalytic fragment of Moloney murine leukemia virus (MoMLV) RT [36], the corresponding region of SFVmac RT harboring amino acid residues 107-368 (RTshort) was constructed. Determination of its specific activity for polymerization on poly(rA)/oligo(dT) indicated a very low polymerization activity $(0.83 \mathrm{U})$, however, the protein was still able to bind double stranded DNA, albeit with a ca. 100 fold higher $K_{D}$-value $(3.6 \pm$ $0.5 \mu \mathrm{M})$ than the WT enzyme [3]. The ${ }^{1} \mathrm{H} /{ }^{15} \mathrm{~N}-\mathrm{HSQC}$ of RTshort-WT recorded in the absence and presence of $21 \mathrm{mM}$ ATP (58 fold excess) revealed no significant chemical shift changes upon ATP addition (Figure 5A), indicating lack of ATP binding, although the concentration is far beyond published physiological values of $<10 \mathrm{mM}$ [37-39].

However, with AZT resistant RTshort-mt4 several significant chemical shift changes upon ATP addition (48-fold excess) could be observed, demonstrating ATP binding. Since S345T is the only single amino acid exchange exhibiting AZTMP excision activity (Figure 2C), we reversed the S345T exchange in RTshort- $m t 4$ back to WT (=RTshort- $m t 4-\mathrm{T} 345 \mathrm{~S})$ and recorded ${ }^{1} \mathrm{H} /{ }^{15} \mathrm{~N}$-HSQC spectra in the absence and presence of ATP (Figure 5C). Even at a 59-fold excess of ATP no chemical shift changes were detectable in the spectrum of RTshort$m t 4$-T345S. This result indicates a key role of the S345T substitution in AZT resistance via creating an ATP binding pocket, which is necessary for the excision mechanism.

Assignment of protein backbone resonances by TROSY-based triple resonance NMR analyses using a ${ }^{2} \mathrm{H} /{ }^{15} \mathrm{~N} /{ }^{13} \mathrm{C}$ labeled RTshort- $m t 4$ sample failed due to insufficient sample stability (precipitation) over the course of the experiments. Using the initially recorded HNCA experiment together with known chemical shift regions, the ${ }^{1} \mathrm{H}$ chemical shift signals between 10.0 and $10.5 \mathrm{ppm}$ in the ${ }^{1} \mathrm{H} /{ }^{15} \mathrm{~N}$ HSQC spectrum could be identified as tryptophan residues (indol-NH resonances). Typically, the indol-NH-resonances are located in the chemical shift range between 9.5 and $10.5 \mathrm{ppm}[40,41]$. Comparison of the spectra (Figure 5, boxes a) proves that a Trp residue is involved in ATP binding in RTshort- $m t 4$, since a chemical shift change is detectable in the relevant ppm-range (Figure 5B, box a). Obviously, this Trp residue is obscured in RTshort-WT as well as in RTshort$m t 4$-T345S. The chemical shift change of a Trp residue 
A

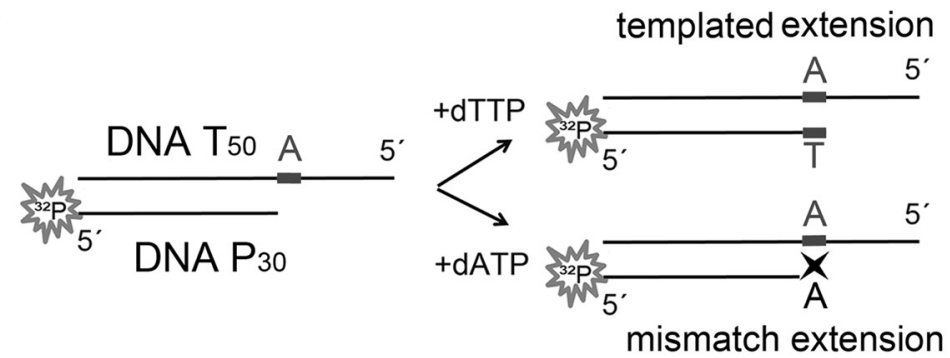

B
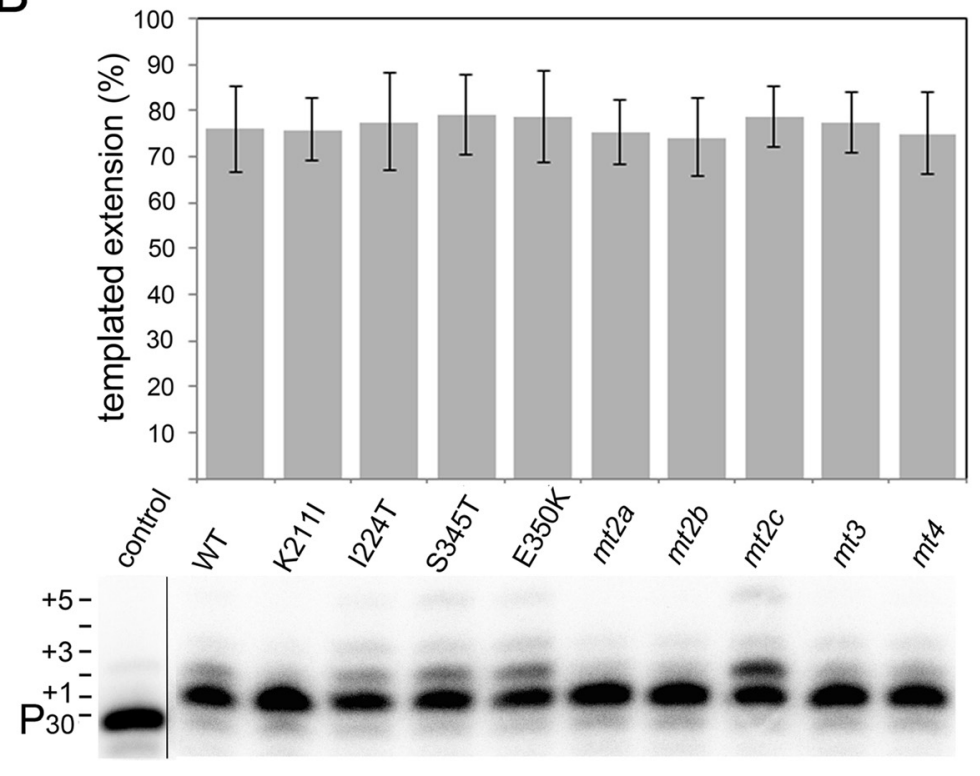

C

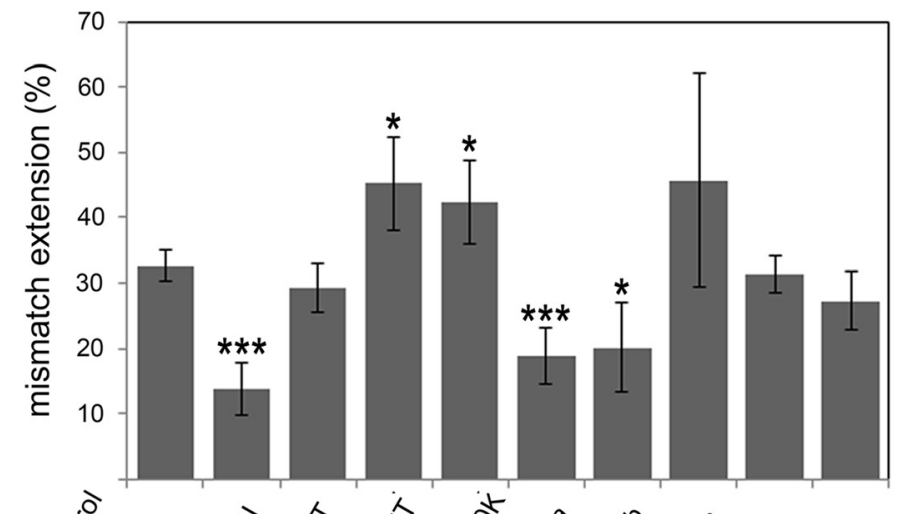

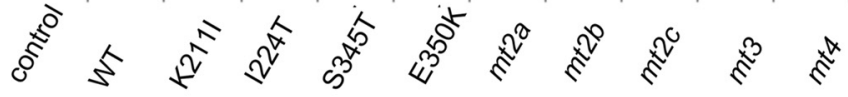

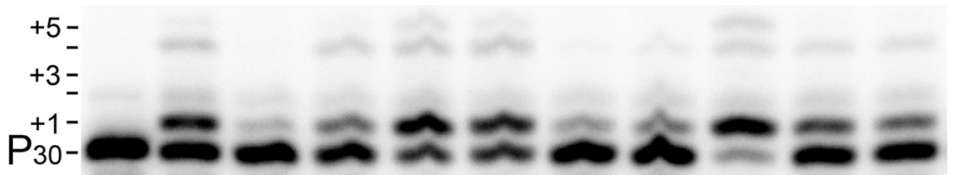


(See figure on previous page.)

Figure 4 Fidelity of PR-RTs. $20 \mathrm{nM}$ of a $5^{\prime 32} \mathrm{P}$ endlabeled $\mathrm{P}_{30} / \mathrm{T}_{50} \mathrm{dA}$ DNA/DNA substrate was incubated with $1.25 \mathrm{mM}$ of the correct (dTTP) or incorrect (dATP) nucleotide for polymerization. Reaction products were separated on a 10\% sequencing gel. (A) Schematic representation of primer extension with the correct nucleotide and primer extension after one nucleotide mismatch. (B) Primer extensions in the presence of the next templated nucleotide (dTTP). Control, assay without enzyme. The diagram (top) depicts the mean values and standard deviations (black bars) of three independent experiments. The autoradiogram (bottom) shows the result of a typical extension experiment. The length of the extensions $\left(P_{31}\right.$ to $\left.P_{35}\right)$ is indicated on the left. Since the bands above $P_{31}$ all comprise the first correct dTTP incorporation they were also included in quantification of the primer extension. For quantification of the extended products the total amount of labeled DNA per lane was set to 100\%. (C) Mismatch primer extensions in the presence of a non-templated nucleotide (dATP). Evaluation of the results as in (B). P-values $\leq 0.05$ represent statistically significant differences to the WT protein (* $p$-value $\leq 0.05 ;{ }^{* *} p$-value $\leq 0.01 ; * * *$-value $\leq 0.001$ ).

suggests a direct contact of that residue with ATP via $\pi-$ $\pi$ interactions, very similar to the interactions between ATP and F/Y215 in HIV-1 RT [15]. In the highly AZT resistant SFVmac PR-RT the substitution S345T might alter the surface exposed residues in its vicinity and thus makes a Trp residue more accessible for hydrophobic interactions with ATP. In contrast to HIV-1 RT, AZT resistance substitutions in SFVmac PR-RT do not result in an aromatic amino acid, but instead make an already existent Trp accessible to fulfill a similar task as the T215Y/F exchange in HIV-1 RT.

\section{Dissociation constant for ATP binding}

To assess the $\mathrm{K}_{\mathrm{D}}$-value for ATP binding in RTshort-mt4 we needed to improve the quality of the spectra. Therefore, RTshort- $m t 4$ was deuterated in addition to ${ }^{15} \mathrm{~N}$ labeling to allow the recording of TROSY ${ }^{1} \mathrm{H} /{ }^{15} \mathrm{~N}$-HSQC spectra (Figure 6A). Application of this technique resulted in sharper NMR signals owing to reduced transverse relaxation and rendered faster recording of the spectra possible. Thus, sample stability problems, i.e. precipitation during NMR measurements, could be overcome.

In a series of ${ }^{1} \mathrm{H},{ }^{15} \mathrm{~N}$ correlation experiments with increasing ATP concentrations, several signals showed the typical gradual change of chemical shifts observed for fast chemical exchange on the NMR time scale. The actual chemical shift in such a spectrum represents the population average of the signal frequencies in the free and bound state, allowing the determination of the dissociation constant in a series of titration experiments. The average $K_{D}$-value for ATP from seven shifting signals in the HSQC spectrum was $7.6( \pm 2.4) \mathrm{mM}$. (Figure $5 \mathrm{~B}$ ). This $\mathrm{K}_{\mathrm{D}}$-value is in the range of published physiological concentrations for ATP in the low millimolar range [37-39].

To analyze how the resistance substitutions alter the ATP binding affinity in the full-length PR-RT enzymes we determined $\mathrm{K}_{\mathrm{M}^{-}}$and $\mathrm{v}_{\max }$-values for ATP using varying ATP concentrations in AZTMP excision assays (Table 3). The kinetic parameters were only defined for those enzyme variants capable of excising AZTMP in the presence of ATP (Figure 2C). While $\mathrm{K}_{\mathrm{M}^{-}}$-values for S345T, $m t 2 a$ and $m t 2 c$ were comparable, significantly lower $\mathrm{K}_{\mathrm{M}^{-}}$-values were measured with $m t 3$ and $m t 4$, again indicating that the combination of the three exchanges K211I, S345T and E350K is necessary for high affinity ATP binding and thus for efficient AZTMP removal.

\section{Conclusions}

We were able to assign different functions to the residues in SFVmac RT responsible for AZT resistance. S345T is probably the first exchange since it is the only single amino acid exchange conferring moderate AZT resistance. Thus, S345T is essential for AZT resistance. It appears to make a Trp residue in the palm subdomain accessible for ATP binding by $\pi-\pi$ stacking interactions of the aromatic rings, thus establishing a new ATP binding site in the enzyme variant that does not exist in the WT. Figure 7 shows a model of SFVmac RT $m t 4$ highlighting the localization of the seven Trp residues that are present in the fingers and palm subdomains. The spacefilling representation (Figure 7B) indicates that most of the Trp residues are located in the inner core of the enzyme and thus do not come into consideration for ATP binding. However, residue W258 is close enough to the active site as well as to the essential residue T345. Furthermore, it is not positioned in the enzyme's interior and thus might be the Trp residue qualifiying for ATP binding. Our results are in strong contrast to AZTresistant HIV-1 RT, in which a second ATP binding site is created in the enzyme (site II) ca. $10 \AA$ away from site I, by introducing the aromatic substitution T215F/Y [15-17].

In SFVmac RT the substitution E350K improves the catalytic efficiency of dNTP incorporation, thereby compensating the reduced polymerization activity caused by K211I in $m t 3$ and $m t 4$. K211I increases fidelity by reducing dNTP affinity, thus facilitating dissociation of a non-complementary dNTP.

The $K_{D}$-value for ATP of RTshort- $m t 4$, harboring the new ATP binding site, is ca. $7.6 \mathrm{mM}$. This is in good agreement with published cellular ATP concentrations [37-39] and the ATP concentration (5 mM) we successfully used for in vitro AZTMP excision experiments. In HIV-1, the binding sites for ATP and the incoming dNTP overlap [15,42]. Obviously, the affinity for ATP needs to be lower than that for the dNTP since otherwise ATP binding would inhibit polymerization in the 

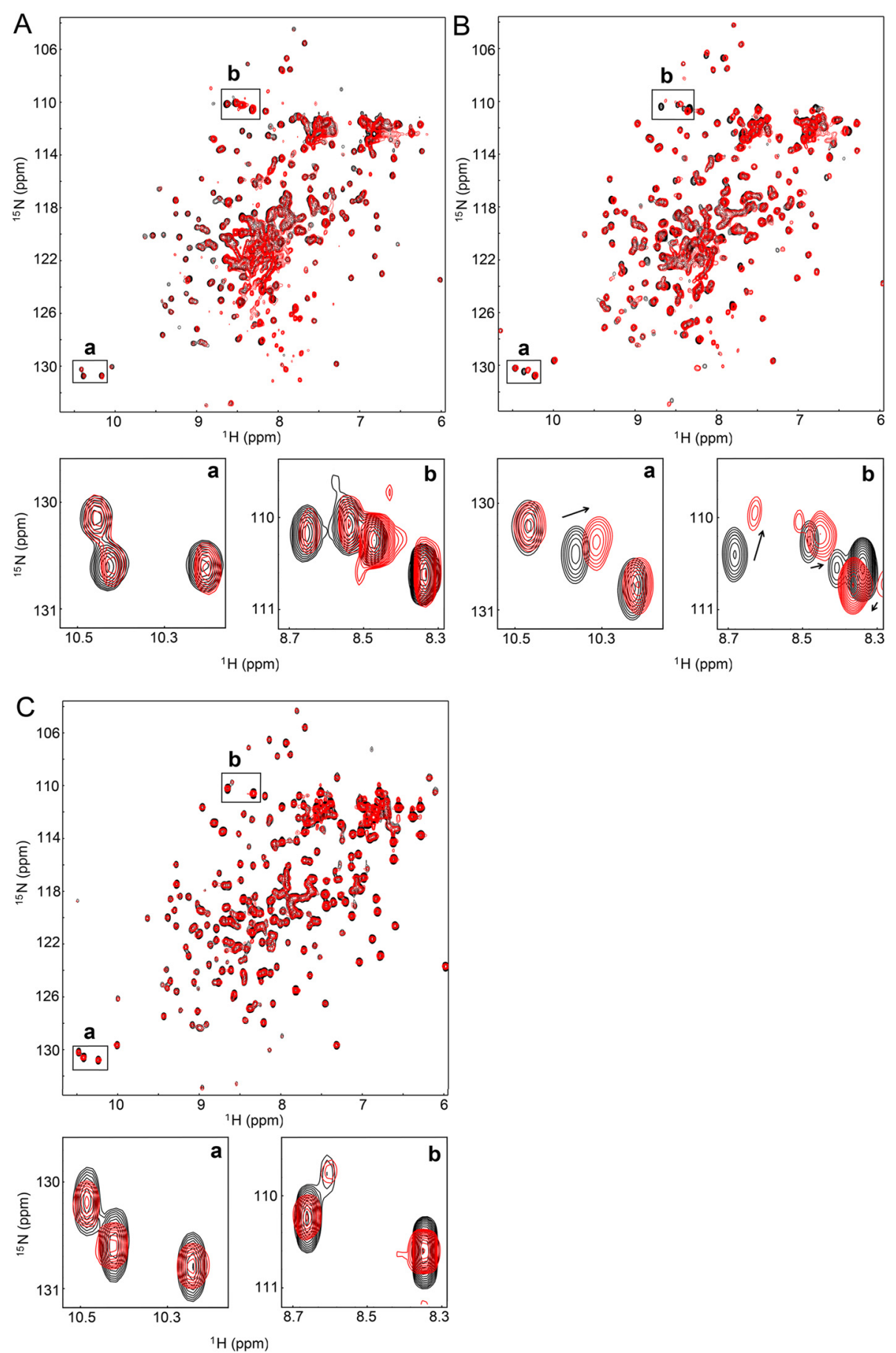

Figure 5 HSQC spectra of RTshort-WT, RTshort-mt4 and RTshort-mt4-T345S. Overlays of ${ }^{1} \mathrm{H} /{ }^{15} \mathrm{~N}-\mathrm{HSQC}$ spectra of RTshort proteins in the absence of ATP (black) and in the presence of $21 \mathrm{mM}$ ATP (red) in binding buffer with 10\% $\mathrm{D}_{2} \mathrm{O}$ at a sample temperature of $298 \mathrm{~K}$. (A) black: $460 \mu \mathrm{M}$ RTshort-WT without ATP; red: $363 \mu \mathrm{M}$ RTshort-WT with a 58 fold ATP excess. (B) black: $550 \mu \mathrm{M}$ RTshort-mt4 without ATP; red: $434 \mu \mathrm{M}$ RTshort with a 48 fold ATP excess. (C) black: RTshort-mt4-T345S without ATP; red: $355 \mu$ M RTshort-mt4-T345S with a 59 fold ATP excess

absence of AZTTP. Nevertheless, ATP binding can be achieved when AZTMP is incorporated due to pausing of the RT in the so-called pre-translocation complex in which the binding pocket for the dNTP is not accessible [16].
In addition to ATP binding, the excision mechanism further requires formation of a phosphodiester bond between ATP and the incorporated AZTMP, followed by the dissociation of the putative excision product, dinucleoside 


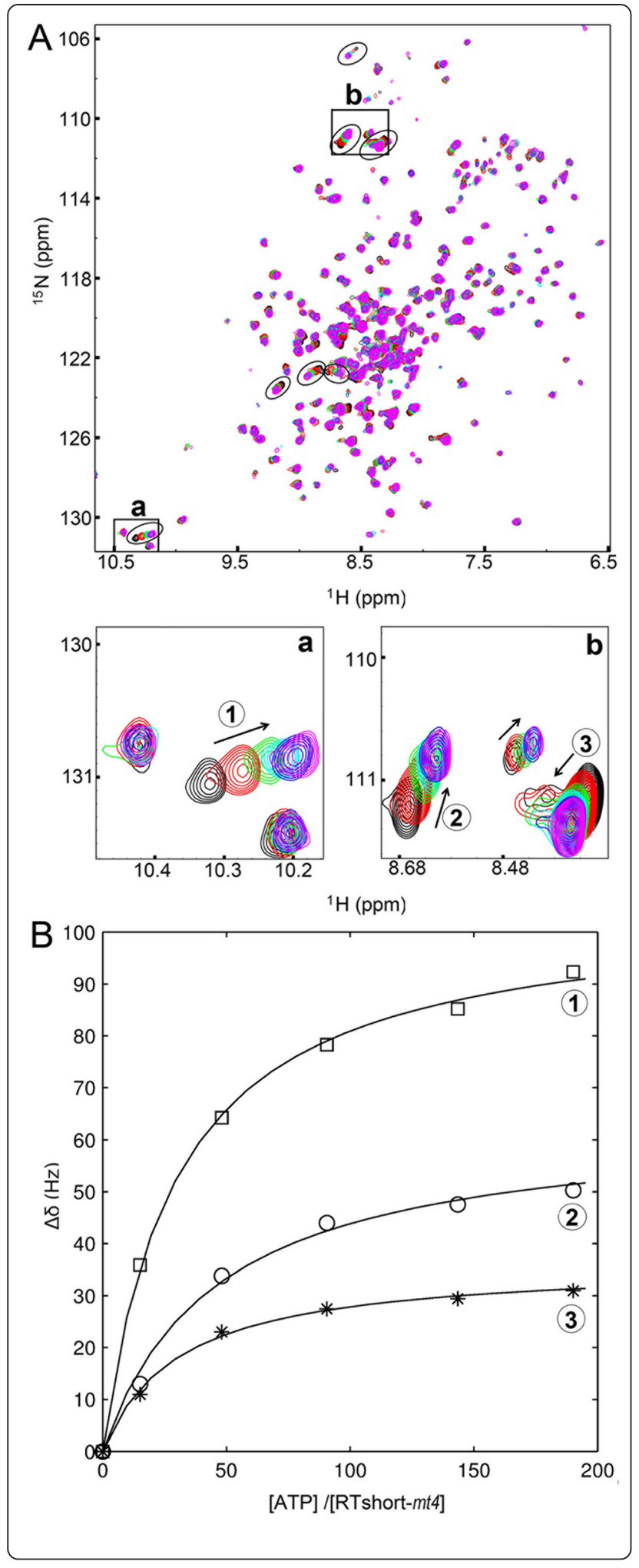

Figure 6 Titration of RTshort-mt4 with ATP. (A) Overlay of TROSY $-{ }^{1} \mathrm{H} /{ }^{15} \mathrm{~N}$-HSQC spectra of $205 \mu \mathrm{M}$ RTshort-mt4 recorded at a sample temperature of $288 \mathrm{~K}$ during the titration with different ATP/ protein ratios. Key: black: 0; red: 15; green: 48; cyan: 92; blue: 142; pink: 195. Blow-ups of the framed areas (a) and (b) are shown underneath the spectra and represent examples of significant chemical shift changes with RTshort-mt4 and ATP. (B) Determination of the mean $K_{D}$-value for ATP with RTshort-mt4. Seven fits for normalized chemical shift changes of seven shifting residues encircled in (A) were used to calculate the mean $K_{D}$-value with standard deviation. Exemplified, fitted curves for three signal changes depicted in boxes (a) and (b) are shown as a function of the $[$ ATP]/[RTshort- $m$ t4] ratio.

tetraphosphate (AZT- $\mathrm{P}_{4}$-A) [12]. Due to its reduced affinity for nucleotides K211I might facilitate the dissociation of the AZT-P ${ }_{4}-\mathrm{A}$, thereby improving the excision reaction in the presence of S345T. Moreover, K211I reduces viral fitness which is at least in part due to the impaired polymerization activity. This, in turn, is compensated by I224T, which improves viral fitness but is not directly involved in the AZT excision process. The amino acid exchange S345T can be achieved by a single nucleotide exchange (TCA > ACA). Therefore, moderately AZT resistant virus is created very easily. This might be the reason why the AZTMP removal pathway is favored over AZTTP discrimination. The functions of the other exchanges are important to obtain highly resistant virus, with improved fidelity and polymerization activity, combined with recovered viral fitness. Thus, although HIV-1 and SFVmac achieve AZT resistance by removal of the incorporated AZTMP, the function of the resistance mutations appear to be different.

\section{Methods}

\section{Cloning, expression and protein purification}

Construction of WT, $m t 3$, and $m t 4$ SFVmac PR-RTs was published previously [14]. The single and double mutants (Figure 2A) were created by site-directed mutagenesis according to the QuickChange protocol from Stratagene (Heidelberg, Germany). Gene expression and protein purification of all SFVmac PR-RT variants was performed using published protocols [14].

Table 3 Kinetic parameters for AZTMP removal by ATP in SFVmac PR-RTs

\begin{tabular}{lllll}
\hline Enzyme & $\mathrm{K}_{\mathbf{M}}(\boldsymbol{\mu M})$ & $\mathbf{p}$-value & $\mathbf{V}_{\max }(\mathrm{nM} / \mathbf{m i n})$ & $\mathrm{p}$-value \\
\hline $\mathbf{S 3 4 5 T}$ & $811( \pm 127)$ & 0.004 & $110.7( \pm 6.7)$ & 0.02 \\
$\boldsymbol{m t 2 a}$ & $893( \pm 268)$ & 0.011 & $112.4( \pm 14.7)$ & 0.08 \\
$\boldsymbol{m t 2 c}$ & $899( \pm 73)$ & 0.001 & $108.7( \pm 11.2)$ & 0.06 \\
$\boldsymbol{m} \boldsymbol{t} \mathbf{m}$ & $142( \pm 44)$ & 0.226 & $100.5( \pm 22.5)$ & 0.14 \\
$\boldsymbol{m} \boldsymbol{4}$ & $241( \pm 101)$ & - & $131.2( \pm 5.6)$ & - \\
\hline
\end{tabular}

The $p$-values were calculated with the unpaired $t$-test, each variant was compared with the highly resistant $m t 4$ variant. $p$-values $\leq 0.05$ were considered significant. 

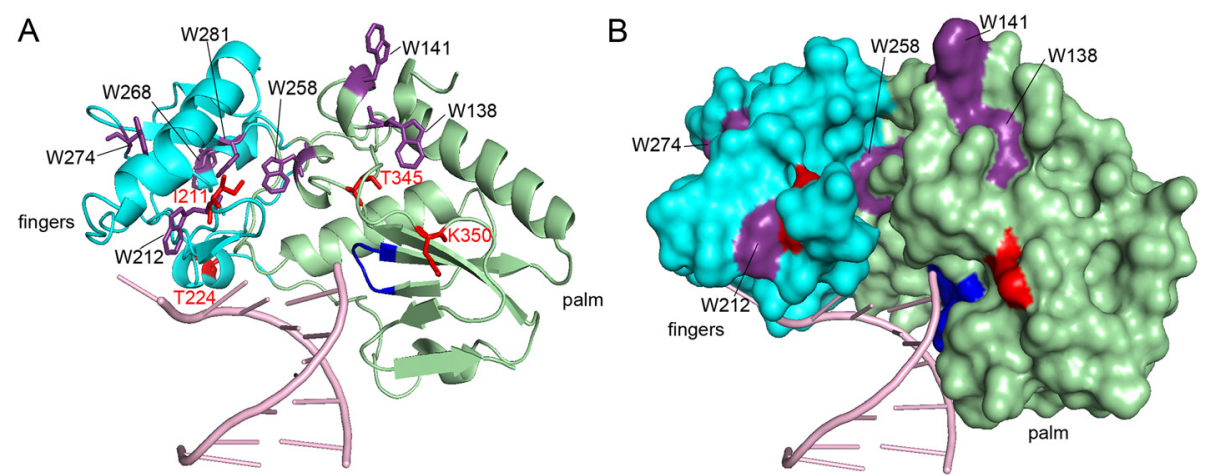

Figure 7 Localization of tryptophan residues in RTshort $m t 4$. A structure homology model was generated based on the structure of XMRV RT (PDB: 4HKQ) using the Program SWISS-MODEL. Color coding is analogous to Figure 1. The Trp residues are highlighted in purple. (A) Ribbon diagram and (B) space filling representation of the fingers and palm subdomains of $m+4$.

SFVmac RTshort-WT, $-m+4$ and -mt4-T345S, coding for amino acid residues 107-368 of the PR-RT, were cloned into the vector pET-GB1a (G. Stier, EMBL, Heidelberg, Germany), expressed as 6His-GB1a fusion proteins, and purified as published previously for prototype foamy virus (PFV) RNase $\mathrm{H}$ [43]. In brief, for ${ }^{1} \mathrm{H} /{ }^{15} \mathrm{~N}$ HSQC experiments, gene expression in Escherichia coli Rosetta DE3 (Novagen/EMD Biosciences; Darmstadt, Deutschland) was induced with $1 \mathrm{mM}$ isopropylthiogalactoside (IPTG) at an optical density at $600 \mathrm{~nm}$ of 0.7 at $20^{\circ} \mathrm{C}$ in $\mathrm{M} 9$ medium supplemented with trace element solution TS2 [44,45], 1 x MEM vitamin solution (Gibco, Karlsruhe, Germany), $1.5 \mathrm{~g} / \mathrm{l}\left({ }^{15} \mathrm{NH}_{4}\right)_{2} \mathrm{SO}_{4}$ (Cambridge Isotope laboratories, Inc., Andover, MA, USA), and $2.5 \%$ of ${ }^{15} \mathrm{~N}$ labeled rich medium (Silantes, Munich, Germany). In order to obtain ${ }^{2} \mathrm{H} /{ }^{15} \mathrm{~N}$ - and ${ }^{2} \mathrm{H} /$ ${ }^{15} \mathrm{~N} /{ }^{13} \mathrm{C}$ - labeled RTshort- $m t 4$ for the TROSY ${ }^{1} \mathrm{H} /{ }^{15} \mathrm{~N}$ HSQC pre-cultures were grown as above or additionally with $4 \mathrm{~g} / \mathrm{l}^{13} \mathrm{C}$-glucose (Euriso-Top, GIF-SUR-YVETTE, France), using a stepwise increase of $\mathrm{D}_{2} \mathrm{O}$ concentrations from $50 \%$ and $75 \%$ up to a final concentration of $100 \%$. After cell lysis the proteins were purified by Ni-affinity chromatography. The 6His-GB1a-tag was cleaved off by tobacco etch virus (TEV) protease and the tag was removed using a second Ni-affinity chromatography. The free RTshort variants were collected in the flow through.

\section{Quantitative polymerization assay}

Measurements of RNA-dependent DNA polymerase activity to determine the specific activity (SPAC) were carried out on a poly $(\mathrm{rA}) / \mathrm{oligo}(\mathrm{dT})_{15}$ substrate $(0.2 \mathrm{U} / \mathrm{ml})$ (Roche Diagnostics GmbH, Mannheim, Germany) as discribed previously [14]. Under these conditions 1 unit (U) of enzyme activity enables the incorporation of $1 \mathrm{nmol}$ TMP into poly(rA)/oligo(dT) $)_{15}$ after $10 \mathrm{~min}$ at $37^{\circ} \mathrm{C}$.

To determine $\mathrm{K}_{\mathrm{M}^{-}}$and $\mathrm{v}_{\max }$ - values, different dTTP concentrations of $25,50,75,125,250,600 \mu \mathrm{M}$ were used in the polymerization reactions and data were fitted to the Michaelis-Menten equation (1) using the fitting program GraFit 5.0.12 (Erithacus Software limited, West Sussex, UK):

$$
\mathrm{v}=\frac{\mathrm{v}_{\max } \cdot[\mathrm{dTTP}]}{\mathrm{K}_{\mathrm{M}}+[\mathrm{dTTP}]}
$$

\section{$5^{\prime}$ endlabeling of primers}

$5^{\prime}{ }^{32} \mathrm{P}$-endlabeling of the $\mathrm{P}_{30}$ primer (5'-GCTGTAATG GCGTCCCTGTTCGGGCGCCTC) (biomers.net; Ulm, Germany) as well as the corresponding AZTMP terminated $\mathrm{P}_{30}$ primer $\left(\mathrm{P}_{30 \text {-AZTMP }}\right)$ was done as described previously $[3,14]$.

\section{Polymerization initiation reactions}

Polymerization assays were performed using a $5^{\prime}{ }^{32} \mathrm{P}$ endlabeled $\mathrm{P}_{30} / \mathrm{T}_{50}$ substrate (template 5'-GCTGTGGA AAATCTCATGCAGAGGCGCCCGAACAGGGACGC CATTACAGC), $250 \mu \mathrm{M}$ of each dNTP and PR-RT as described previously [4].

\section{Qualitative RNase $\mathrm{H}$ assay}

The RNA template (5' AACAGAGUGCGACACCUG AUUCCAU) (Metabion GmbH, Planegg-Martinsried, Germany) was ${ }^{32} \mathrm{P}$-labeled at its 5 ' end and hybridized to a DNA primer (5' TGGAATCAGGTGTCGCACTCTG) (Metabion $\mathrm{GmbH}$, Planegg-Martinsried, Germany) using a 1.2 fold excess of the DNA [3,14]. RNase $\mathrm{H}$ reactions were performed with $240 \mathrm{nM} \mathrm{RNA}{ }_{25} / \mathrm{DNA}_{22}$ hybrid and $50 \mathrm{nM}$ RT-PR for $2 \mathrm{~min}$ at $25^{\circ} \mathrm{C}$. Reactions were stopped by the addition of an equal volume of urea loading buffer $(0.1 \%$ bromophenol blue, $0.1 \%$ xylene cyanol, $8 \mathrm{M}$ urea, $89 \mathrm{mM}$ Tris/ $\mathrm{HCl} \mathrm{pH} \mathrm{8.3,} 89 \mathrm{mM}$ boracic acid) supplemented with $50 \mathrm{mM}$ ethylenediaminetetraacetate (EDTA). Reaction products were separated by denaturing gel electrophoresis (10\% polyacrylamide/8 M urea 
gels). Products were visualized using a phosphoimaging device (Dürr Medical CR 35 Bio; Bietigheim-Bissingen, Germany) and quantified densitometrically with the software AIDA Image Analyzer V.450 (raytest, Staubenhardt, Germany).

\section{Fluorescence equilibrium titrations}

To determine dissociation constants $\left(\mathrm{K}_{\mathrm{D}}\right)$ for DNA binding, changes in anisotropy were measured by fluorescence equilibrium titrations with $5 \mathrm{nM}$ of a 24/40-mer DNA/DNA (primer 5' -ATCACCAGGAGAGGGGAAA GCGGA, template 5'-DY647-CTAATTCCGCTTTCCC CTCTCCTGGTGATCCTTTCCATCC) (biomers.net GmbH, Ulm, Germany) and increasing amounts of enzyme at $25^{\circ} \mathrm{C}$. $\mathrm{K}_{\mathrm{D}}$-values were calculated via non-linear curve fitting of the anisotropy data to a two component binding equation as described previously [43].

\section{AZTMP excision}

The $\mathrm{P}_{30}$ DNA primer was terminated with AZTTP as described [14]. Subsequently, the resulting $\mathrm{P}_{30 \text {-AzTMP }}$ was purified via gel electrophoresis on a $20 \%$ denaturing polyacrylamide/8 $\mathrm{M}$ urea gel followed by UV shadowing to identify the DNA. After cutting out of the correct band, the DNA was electro-eluted, dialyzed against $\mathrm{H}_{2} \mathrm{O}$ and lyophilized. 100 pmoles of $5^{\prime}-\left[{ }^{32} \mathrm{P}\right]$ endlabeled $\mathrm{P}_{30-}$ AZTMP DNA were hybridized to a 1.2-fold molar excess of the $\mathrm{T}_{50}$ template DNA as described $[4,14] .5 \mathrm{nM} \mathrm{P}_{30}$ AZTMP $/ \mathrm{T}_{50}, 0.02 \mathrm{U}$ of pyrophosphatase (Sigma-Aldrich Chemie GmbH, Taufkirchen, Germany) and $5 \mathrm{mM}$ ATP (Jena Bioscience, Jena, Germany) were preincubated for $5 \mathrm{~min}$ at $37^{\circ} \mathrm{C}$ in reaction buffer in a total volume of $10 \mu \mathrm{l}$. AZTMP excision reactions were started by the addition of $320 \mathrm{nM}$ enzyme, carried out for $20 \mathrm{~min}$ at $37^{\circ} \mathrm{C}$ and stopped by adding $10 \mu \mathrm{l}$ of urea loading buffer with $25 \mathrm{mM}$ EDTA. Reaction products were separated by denaturing gel electrophoresis and quantified as described above.

To determine the $\mathrm{K}_{\mathrm{M}^{-}}$and $\mathrm{v}_{\max }$-values for ATP excision identical conditions were applied. However, ATP concentrations were varied, using $0.0,0.15,0.3,0.5,1.0$, 2.0 or $3 \mathrm{mM}$ ATP. $\mathrm{K}_{\mathrm{M}^{-}}$and $\mathrm{v}_{\max }$-values were obtained using Hanes-Woolf linearization of the MichaelisMenten equation.

\section{Polymerase fidelity measurements}

A 50mer DNA template $\left(\mathrm{T}_{50} \mathrm{dA}\right)$ (5' - GCTGTGGCCG GTCTCTTGTAGAGGCGCCCGAACAGGGACGCCA TTACAGC) was hybridized to a $5^{\prime}{ }^{32}$ P-labeled DNA primer $\left(\mathrm{P}_{30}\right)$ (5' -GCTCTAATGGCGTCCCTGTTCGG GCGCCTC) (biomers.net; Ulm, Germany) [4]. $20 \mathrm{nM}$ of the $\mathrm{T}_{50} \mathrm{dA} / \mathrm{P}_{30}$ substrate were pre-incubated for 2 min at $37^{\circ} \mathrm{C}$ with $0.08 \mathrm{U}$ of pyrophosphatase (Sigma Aldrich Chemie GmbH, Taufkirchen, Germany) and
$1.25 \mathrm{mM}$ dATP (mismatch) or dTTP (match) in reaction buffer. Reactions were started by the addition of $1.25 \mu \mathrm{M}$ enzyme and stopped after $12 \mathrm{~min}$ with an equal volume of urea loading buffer (see above). The reaction products were separated via denaturing gel electrophoresis (8\% polyacrylamide/8 M urea gels) and analyzed as described above. Since the bands above $\mathrm{P}_{31}$ all comprise the first correct dTTP incorporation they were also included in quantification of the primer extensions. Mean values and standard deviations of at least three independent experiments were analyzed in unpaired $t$-tests. Significant differences to the WT enzyme are indicated as $\mathrm{p}$-values in Additional file 1: Table $\mathrm{S} 1$ and in Figure $4 \mathrm{C}$ by asterisks.

\section{ATP binding experiments}

2D $\left[{ }^{1} \mathrm{H}_{-}{ }^{15} \mathrm{~N}\right] \mathrm{HSQC}$ experiments were recorded in the absence and presence of ATP $(21 \mathrm{mM})$ (Jena Bioscience, Jena, Germany) with RTshort-WT, RTshort-mt4 and RTshort-mt4-T345S in binding buffer $[50 \mathrm{mM}$ Tris/HCl pH $\left.6.7_{25^{\circ} \mathrm{C}}, 150 \mathrm{mM} \mathrm{NaCl}, 6 \mathrm{mM} \mathrm{MgCl} 2,0.5 \mathrm{mM} \mathrm{DTT}\right]$ with $10 \%(\mathrm{v} / \mathrm{v}) \mathrm{D}_{2} \mathrm{O}$ at $298 \mathrm{~K}$. To determine the $\mathrm{K}_{\mathrm{D}}$-value for ATP of RTshort- $m t 4$, transverse relaxationoptimized spectroscopy (TROSY) ${ }^{1} \mathrm{H} /{ }^{15} \mathrm{~N}$-HSQC experiments $[46,47]$ were done with $205 \mu \mathrm{M}$ of deuterated and ${ }^{15} \mathrm{~N}$ labeled ${ }^{2} \mathrm{H} /{ }^{15} \mathrm{~N}$ RTshort-mt4 in binding buffer. ${ }^{1} \mathrm{H}$ back-exchange of amide protons was achieved by overnight dialysis of the protein against binding buffer at $4^{\circ} \mathrm{C}$. Comparison with spectra of ${ }^{15} \mathrm{~N}$-labeled protein demonstrated the nearly complete back-exchange of amide protons. A TROSY ${ }^{1} \mathrm{H} /{ }^{15} \mathrm{~N}-\mathrm{HSQC}$ spectrum of RTshort- $m t 4$ was recorded without ATP and after the addition of ATP at various molar ratios as indicated in Figure 6. The $\mathrm{K}_{\mathrm{D}}$-values for ATP of seven different shifting signals were determined by fitting the chemical shift changes of the TROSY ${ }^{1} \mathrm{H} /{ }^{15} \mathrm{~N}$-HSQCs to a two-state model (equation 2). $\delta_{\mathrm{obs}}, \delta_{\mathrm{P}}$ and $\delta_{\mathrm{PL}}$ are the chemical shifts for the protein in the ATP-bound and -unbound state, the free RTshort-mt4, and the ATP/RTshort- $m t 4$ complex, respectively. $\left[P_{O}\right]$ is the total protein concentration and $r$ describes the ration of ATP and protein concentration, [ATP]/[RTshort-mt4].

$$
\begin{aligned}
\Delta \delta_{\text {obs }}= & \delta_{P}+\left(\delta_{P L}-\delta_{P}\right) . \\
& {\left[\frac{\left\{K_{D}+(1+r)\left[P_{0}\right]\right\}-\sqrt{\left\{K_{D}+(1-r)\left[P_{0}\right]\right\}^{2}-4\left[P_{0}\right]^{2} r}}{2\left[P_{0}\right]}\right] }
\end{aligned}
$$

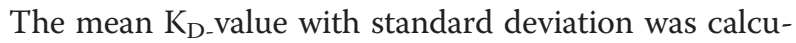
lated using the independent fits of the seven shifting residues. TROSY based triple resonance experiments [48] were recorded for protein backbone assignment using a ${ }^{2} \mathrm{H} /{ }^{13} \mathrm{C} /{ }^{15} \mathrm{~N}$ labeled sample. All spectra were acquired 
on Bruker Avance 700 and $800 \mathrm{MHz}$ spectrometers equipped with cryogenically cooled probes. The NMR data was processed applying in house protocols and analyzed with the program NMRView (B. A. Johnson; Merck, Whitehouse Station, NJ, USA).

\section{Additional file}

Additional file 1: Table S1. Fidelity of PR-RTs. Quantification of the primer extension reactions with a templated (match) and non-templated (mismatch) dNTP represented in Figure 3.

\section{Abbreviations}

AZT: Azidothymidine; FV: Foamy virus; GB1a: Immunoglobulin binding domain B1 of streptococcal protein G; HIV-1: Human immunodeficiency virus type 1; IN: Integrase; IPTG: Isopropyl-thiogalactoside; $\mathrm{K}_{\mathrm{D}}$ : Dissociation constant; NRTI: Nucleoside reverse transcriptase inhibitor; NtRTI: Nucleotide reverse transcriptase inhibitor; SFVmac: Simian foamy virus from macaques; MoMLV: Moloney murine leukemia virus, PR, protease; RNase H: Ribonuclease $\mathrm{H}$; P/T: Primer/template; RT: Reverse transcriptase; TEV: Tobacco etch virus.

\section{Competing interests}

The authors declare that they have no competing interests.

\section{Authors' contributions}

BMW conceived and coordinated the study. AS performed the experiments. BMW, AS and KS analyzed the data. BMW and AS wrote the paper. PR provided conceptual input and financial support. All authors read and approved the manuscript.

\section{Acknowledgement}

The authors thank Ulrike Persau and Ramona Heissmann for excellent technical assistance, and Dr. Maximilian J. Hartl for helpful discussions. This work was supported by the Deutsche Forschungsgemeinschaft (grant number Wo630/7-3), the University of Bayreuth, the Bavarian International Graduate School of Science (BIGSS), the Bayreuth Graduate School of Mathematical and Natural Sciences (BayNat), and the Stabsabteilung Chancengleichheit, University of Bayreuth.

Received: 22 September 2014 Accepted: 27 January 2015 Published online: 22 February 2015

\section{References}

1. Goff SP. Retroviridae: the retroviruses and their replication. In: Knipe DM, Howley PM, editors. Fields virology. Philadelphia: Lippincott Williams \& Wilkins; 2007. p. 1999-2069.

2. Linial ML, Eastman SW. Particle assembly and genome packaging. Curr Top Microbiol Immunol. 2003:277:89-110.

3. Hartl MJ, Mayr F, Rethwilm A, Wöhrl BM. Biophysical and enzymatic properties of the simian and prototype foamy virus reverse transcriptases. Retrovirology. 2010;7:5.

4. Schneider A, Peter D, Schmitt J, Leo B, Richter F, Rösch P, et al. Structural requirements for enzymatic activities of foamy virus protease-reverse transcriptase. Proteins. 2014;82:375-85.

5. Hartl MJ, Schweimer K, Reger MH, Schwarzinger S, Bodem J, Rösch P, et al. Formation of transient dimers by a retroviral protease. Biochem $J$. 2010:427:197-203.

6. Hartl MJ, Wöhrl BM, Rösch P, Schweimer K. The solution structure of the simian foamy virus protease reveals a monomeric protein. J Mol Biol. 2008;381:141-9.

7. Hartl MJ, Bodem J, Jochheim F, Rethwilm A, Rösch P, Wöhrl BM. Regulation of foamy virus protease activity by viral RNA - a novel and unique mechanism among retroviruses. J Virol. 2011:85:4462-9.

8. Lee CC, Ye F, Tarantal AF. Comparison of growth and differentiation of fetal and adult rhesus monkey mesenchymal stem cells. Stem Cells Dev. 2006;15:209-20
9. Moebes A, Enssle J, Bieniasz PD, Heinkelein M, Lindemann D, Bock M, et al. Human foamy virus reverse transcription that occurs late in the viral replication cycle. J Virol. 1997;71:7305-11.

10. Rosenblum LL, Patton G, Grigg AR, Frater AJ, Cain D, Erlwein O, et al. Differential susceptibility of retroviruses to nucleoside analogues. Antivir Chem Chemother. 2001:12:91-7.

11. Kretzschmar B, Nowrouzi A, Hartl MJ, Gärtner K, Wiktorowicz T, Herchenröder O, et al. AZT-resistant foamy virus. Virology. 2008;370:151-7.

12. Meyer PR, Matsuura SE, Mian AM, So AG, Scott WA. A mechanism of AZT resistance: an increase in nucleotide-dependent primer unblocking by mutant HIV-1 reverse transcriptase. Mol Cell. 1999;4:35-43.

13. Meyer PR, Matsuura SE, So AG, Scott WA. Unblocking of chain-terminated primer by HIV-1 reverse transcriptase through a nucleotide-dependent mechanism. Proc Natl Acad Sci U S A. 1998;95:13471-6.

14. Hartl MJ, Kretzschmar B, Frohn A, Nowrouzi A, Rethwilm A, Wöhrl BM. AZT resistance of simian foamy virus reverse transcriptase is based on the excision of AZTMP in the presence of ATP. Nucleic Acids Res. 2008;36:1009-16.

15. Tu X, Das K, Han Q, Bauman JD, Clark Jr AD, Hou X, et al. Structural basis of HIV-1 resistance to AZT by excision. Nat Struct Mol Biol. 2010;17:1202-9.

16. Sarafianos SG, Clark Jr AD, Das K, Tuske S, Birktoft JJ, llankumaran P, et al. Structures of HIV-1 reverse transcriptase with pre- and post-translocation AZTMP-terminated DNA. EMBO J. 2002;21:6614-24.

17. Boyer PL, Sarafianos SG, Arnold E, Hughes SH. Selective excision of AZTMP by drug-resistant human immunodeficiency virus reverse transcriptase. J Virol. 2001;75:4832-42.

18. Larder BA, Kemp SD. Multiple mutations in HIV-1 reverse transcriptase confer high-level resistance to zidovudine (AZT). Science. 1989;246:1155-8.

19. Kellam $P$, Boucher CA, Larder BA. Fifth mutation in human immunodeficiency virus type 1 reverse transcriptase contributes to the development of high-level resistance to zidovudine. Proc Natl Acad Sci U S A. 1992:89:1934-8.

20. Arion D, Kaushik N, McCormick S, Borkow G, Parniak MA. Phenotypic mechanism of HIV-1 resistance to 3'-azido-3'-deoxythymidine (AZT): Increased polymerization processivity and enhanced sensitivity to pyrophosphate of the mutant viral reverse transcriptase. Biochemistry. 1998;37:15908-17.

21. Boyer PL, Sarafianos SG, Arnold E, Hughes SH. The M184V mutation reduces the selective excision of zidovudine 5 '-monophosphate (AZTMP) by the reverse transcriptase of human immunodeficiency virus type 1. J Virol. 2002:76:3248-56

22. Nowak E, Potrzebowski W, Konarev PV, Rausch JW, Bona MK, Svergun DI, et al. Structural analysis of monomeric retroviral reverse transcriptase in complex with an RNA/DNA hybrid. Nucleic Acids Res. 2013;41(6):3874-87.

23. Steitz TA. DNA polymerases: Structural diversity and common mechanisms. J Biol Chem 1999:17395-17398.

24. Kohlstaedt LA, Wang J, Friedman JM, Rice PA, Steitz TA. Crystal structure at $3.5 \AA$ resolution of HIV-1 reverse transcriptase complexed with an inhibitor Science. 1992;256:1783-90.

25. Arnold K, Bordoli L, Kopp J, Schwede T. The SWISS-MODEL workspace: a web-based environment for protein structure homology modelling. Bioinformatics. 2006:22:195-201.

26. Das K, Bandwar RP, White KL, Feng JY, Sarafianos SG, Tuske S, et al. Structural basis for the role of the K65R mutation in HIV-1 reverse transcriptase polymerization, excision antagonism, and tenofovir resistance. J Biol Chem. 2009;284:35092-100

27. Garforth SJ, Domaoal RA, Lwatula C, Landau MJ, Meyer AJ, Anderson KS, et al. K65R and K65A substitutions in HIV-1 reverse transcriptase enhance polymerase fidelity by decreasing both dNTP misinsertion and mispaired primer extension efficiencies. J Mol Biol. 2010:401:33-44.

28. Delviks-Frankenberry KA, Nikolenko GN, Boyer PL, Hughes SH, Coffin JM, Jere A, et al. HIV-1 reverse transcriptase connection subdomain mutations reduce template RNA degradation and enhance AZT excision. Proc Natl Acad Sci U S A. 2008;105:10943-8

29. Delviks-Frankenberry KA, Nikolenko GN, Barr R, Pathak VK. Mutations in human immunodeficiency virus type 1 RNase $\mathrm{H}$ primer grip enhance 3'-azido-3'-deoxythymidine resistance. J Virol. 2007:81:6837-45.

30. Nikolenko GN, Delviks-Frankenberry KA, Palmer S, Maldarelli F, Fivash Jr MJ Coffin JM, et al. Mutations in the connection domain of HIV-1 reverse transcriptase increase 3'-azido-3'-deoxythymidine resistance. Proc Natl Acad Sci U S A. 2007:104:317-22

31. Shah FS, Curr KA, Hamburgh ME, Parniak M, Mitsuya H, Arnez JG, et al. Differential influence of nucleoside analog-resistance mutations K65R and L74V on the overall mutation rate and error specificity of human 
immunodeficiency virus type 1 reverse transcriptase. J Biol Chem. 2000;275 (35):27037-44

32. Boyer PL, Hughes SH. Analysis of mutations at position 184 in reverse transcriptase of human immunodeficiency virus type 1. Antimicrob Agents Chemother. 1995;39:1624-8.

33. Back NK, Nijhuis M, Keulen W, Boucher CA, Oude Essink BO, van Kuilenburg $A B$, et al. Reduced replication of 3TC-resistant HIV-1 variants in primary cells due to a processivity defect of the reverse transcriptase enzyme. EMBO J. 1996;15:4040-9.

34. Oude Essink BB, Back NK, Berkhout B. Increased polymerase fidelity of the 3TC-resistant variants of HIV-1 reverse transcriptase. Nucleic Acids Res. 1997;25:3212-7.

35. Sluis-Cremer N, Arion D, Kaushik N, Lim H, Parniak MA. Mutational analysis of Lys65 of HIV-1 reverse transcriptase. Biochem J. 2000;348(Pt 1):77-82.

36. Georgiadis MM, Jessen SM, Ogata CM, Telesnitsky A, Goff SP, Hendrickson WA. Mechanistic implications from the structure of a catalytic fragment of moloney murine leukemia virus reverse transcriptase. Structure. 1995;3:879-92.

37. Gavegnano C, Kennedy EM, Kim B, Schinazi RF. The impact of macrophage nucleotide pools on HIV-1 reverse transcription, viral replication, and the development of novel antiviral agents. Mol Biol Int. 2012;2012:625983.

38. Kennedy HJ, Pouli AE, Ainscow EK, Jouaville LS, Rizzuto R, Rutter GA. Glucose generates sub-plasma membrane ATP microdomains in single islet beta-cells. potential role for strategically located mitochondria. J Biol Chem. 1999;274:13281-91.

39. Wang RH, Tao L, Trumbore MW, Berger SL. Turnover of the acyl phosphates of human and murine prothymosin alpha in vivo. J Biol Chem. 1997;272:26405-12.

40. Cavanagh J, Fairbrother WJ, Palmer III AG, Rance M, Skelton NJ. Protein NMR spectroscopy: principles and practice. Boston: Academic; 2007.

41. Wishart DS, Sykes BD, Richards FM. Relationship between nuclear magnetic resonance chemical shift and protein secondary structure. J Mol Biol. 1991;222:311-33.

42. Huang HF, Chopra R, Verdine GV, Harrison SC. Structure of a covalently trapped catalytic complex of HIV-1 reverse transcriptase: Implications for drug design. Science. 1998;282:1669-75.

43. Leo B, Hartl MJ, Schweimer K, Mayr F, Wöhrl BM. Insights into the structure and activity of prototype foamy virus RNase H. Retrovirology. 2012;9:14.

44. Sambrook J, Fritsch EF, Maniatis T. Molecular cloning - a laboratory manual. Cold Spring Harbor, NY: Cold Spring Harbor Laboratory Press; 1994.

45. Meyer O, Schlegel HG. Biology of aerobic carbon monoxide-oxidizing bacteria. Annu Rev Microbiol. 1983;37:277-310.

46. Pervushin K. Impact of transverse relaxation optimized spectroscopy (TROSY) on NMR as a technique in structural biology. Q Rev Biophys. 2000;33:161-97.

47. Pervushin $\mathrm{K}$, Riek R, Wider $\mathrm{G}$, Wuthrich $\mathrm{K}$. Attenuated $\mathrm{T} 2$ relaxation by mutual cancellation of dipole-dipole coupling and chemical shift anisotropy indicates an avenue to NMR structures of very large biological macromolecules in solution. Proc Natl Acad Sci U S A. 1997;94:12366-71.

48. Salzmann M, Pervushin K, Wider G, Senn H, Wuthrich K. TROSY in triple-resonance experiments: New perspectives for sequential NMR assignment of large proteins. Proc Natl Acad Sci U S A. 1998:95:13585-90.

\section{Submit your next manuscript to BioMed Central and take full advantage of:}

- Convenient online submission

- Thorough peer review

- No space constraints or color figure charges

- Immediate publication on acceptance

- Inclusion in PubMed, CAS, Scopus and Google Scholar

- Research which is freely available for redistribution 